\title{
Effect of Multimodal Teaching Mode Based on Rain Classroom on Graduates' English Learning Agency
}

\author{
Zhang Hanbin ${ }^{1, *}$ Zanyanjizhaoma $^{2}$ \\ ${ }^{1}$ School of Foreign Languages, Northwest Minzu University, Gansu Province, China \\ ${ }^{2}$ School of Foreign Languages, Northwest Minzu University, Gansu Province, China \\ *Corresponding author.Email: zhanghb06@163.com
}

\begin{abstract}
The purpose of the study is to discuss the effect of multimodal teaching mode based on Rain Classroom on graduates' English learning agency. This paper constructs the multimodal teaching mode of graduates' English based on Rain Classroom. The mode contains three steps---students' preparation before class, students' interaction in class organized by the teacher, and students' after-class seminars. In addition, the study shows that there are no significant differences on autonomous learning between HLG and MLG or between MLG and LLG, but significant differences between HLG and LLG. On the interactive learning, there are significant differences between HLG and MLG and between HLG and LLG, but no significant differences between MLG and LLG.
\end{abstract}

Keywords: Multimodal teaching mode, Rain Classroom, learning agency

\section{INTRODUCTION}

The theory of agency as self-regulation is included in Bandura's social cognitive theory [1], which Martin expounds from the perspective of the history of philosophy of thought [2]. His research explores the significance of self-regulated learning in classroom teaching. In addition, he thinks that the understanding of agency should consider not only social cognitive theory, but also educational psychology, constructivist theory and sociocultural theory. Many researchers have discussed the effect of agency on learning.

There is a consensus that student participation in learning activities is a structure composed of behavioral, emotional and cognitive aspects. Reeve and Tseng recommend agency as an important new aspect. They define it as the student's participation in the process of instruction they receive [3]. They examined the classroom motivations of Taiwanese high school students and their final grades. They used structural equation modeling to analyze the four aspects of participatory learning. The results show that the agency is both a unique and an important aspect of participation. The student's behavior, emotion, cognition and agency together can predict the student's performance. The results of the study by Taub, Sawyer, Smith, Rowe, Azevedo, \& Lester show that in the game learning environment, moderate degree of agency can make students achieve a better learning effect without sacrificing their learning interest and negative emotional experience, and show that even low level of motivation can have a positive effect on learning, problem-solving and game learning [4]. Luo, Yang, Xue, \& Zuo discuss the impact of student agency on learning performance and learning experience in a flipped classroom. Their empirical results reveal that student agency has a significant impact on students' academic performance and perceived learning experience [5].

There are other studies on the influence of agency over learning. Wiliams believes that students with agency are powerful learners who are prepared to deal with the world with sustained, courageous curiosity [6]. Jääskelä et al present a novel approach and a method of learning analytics to study student agency in higher education [7]. Goller \& Paloniemi introduce the function of agency at work, learning and professional development [8]. This paper, from a distinct perspective, will discuss the effect of multimodal teaching mode based on Rain Classroom on graduates' English learning agency.

\section{MULTIMODAL TEACHING MODE BASED ON RAIN CLASSROOM}

The multimodal theory of teaching is the multimodal interaction among students, between teachers and 
students, between students and problems, between teachers and network environment [9]. This multimodal interaction enables students and teachers to communicate effectively to solve problems with the help of the platform of Rain Classroom, and to give each other evaluation and feedback, and can jointly promote the development of the teaching process [10]. Teachers do not make the traditional preparation of learning contents, but with the help of the platform of Rain Classroom to constantly create and update learning contents and design teaching activities. The network not only provides a teaching platform for multimodal interactive teaching among learners, but also provides teachers with diversified teaching means and a large number of information resources. The Rain Classroom broadens the teaching contents, provides many kinds of information presenting ways, and realizes the resources sharing. The network environment is not only helpful for teachers to explore and complete the construction of knowledge and ability, but also helps teachers display the learning contents to the students through PPT to fully mobilize the students' multimodal cognition, and through the Rain Classroom carried on the PPT to supervise and inspect students' learning.

\section{RESEARCH METHODS}

In this study, two graduate classes (92 students) in Northwest Minzu University were selected to conduct the experiment. The two graduate classes are the experimental classes. The experiment lasted one year. This study does questionnaire research on the effectiveness of the multimodal teaching mode based on Rain Classroom on graduates' English learning agency. The graduates are divided into three groups according to their performance on the final exam, with 31 high-level graduates (HLG), 31 mid-level graduates (MLG), and 30 low-level graduates (LLG).

Research questions of this paper are: (1) how is a multimodal teaching mode of graduates' English based on Rain Classroom constructed? And (2) what is the effect of the multimodal teaching mode of junior English based on Rain Classroom on graduates' English learning agency?

\section{RESULTS AND DISCUSSION}

\subsection{The Multimodal Teaching Mode of Graduates' English Based on Rain Classroom}

Rain Classroom platform can connect teachers and students through the Internet to realize the combination of "offline" classroom teaching and "online" network teaching. The multimodal teaching model of English learning for graduate students based on Rain Classroom is as follows. (1) Students' preparation before class. Graduate Students' pre-class English learning is no longer just a simple look at the teaching content, but the preparation of a handout for the teaching content that the teacher has uploaded to the Rain Classroom before the class. (2) Students' interaction in class organized by the teacher. Graduate students show their understanding of the uploaded teaching content in the classroom on the Rain Classroom platform. The teacher organizes students to interact to get the comprehensive understanding of the learning content. (3) Students' after-class seminars. With the help of the Rain Classroom platform, the teacher organizes students to consult relevant materials after class to discuss and expand the learning content, and asks students to upload their seminar materials to the Rain Classroom platform to share in the form of a written report.

\subsection{The Effect of the Multimodal Teaching Mode Based on Rain Classroom on Graduates' English Learning Agency}

After the teaching experiment, a questionnaire survey was conducted in the two experimental classes. The questionnaire was answered with five-point Likert scale, and the five options were assigned 5, 4, 3, 2 and 1 according to the positive response. The data of the questionnaire were analyzed as a whole according to the dimensions. In this study, learning agency can be divided into autonomous learning and interactive learning.

\subsubsection{Graduates’ English Autonomous Learning}

In this part, a one-way ANOVA model is adopted. The factor in the model is graduates' English autonomous learning. The total mean of autonomous learning is 3.518, with HLG the highest (3.667) and LLG the lowest (3.353) (Table 1).

Table 1. Descriptive statistics for learning agency

\begin{tabular}{|c|c|c|c|c|c|c|c|c|}
\hline & \multicolumn{4}{|c|}{ Autonomous learning } & \multicolumn{4}{|c|}{ Interactive learning } \\
\hline Group & $\mathrm{HLG}$ & MLG & LLG & Total & HLG & MLG & LLG & Total \\
\hline Numbe & 31 & 31 & 30 & 92 & 31 & 31 & 30 & 92 \\
\hline Mean & 3.667 & 3.529 & 3.353 & 3.518 & 3.487 & 3.187 & 3.113 & 3.264 \\
\hline$S D$ & 0.534 & 0.365 & 0.413 & 0.457 & 0.564 & 0.467 & 0.481 & 0.527 \\
\hline SEM & 0.096 & 0.066 & 0.075 & 0.048 & 0.101 & 0.084 & 0.088 & 0.055 \\
\hline
\end{tabular}

The results of the one-way ANOVA model (Table 2) show that of the total variance of autonomous learning (18.987), the source of between groups is 1.502 , and the source of within groups 17.485. The $F$ value of the model is 3.824 and the $\mathrm{P}$ value is $0.026<0.05$, which shows that this model is effective in the analysis of variance of the three groups. 
Table 2. Results of the one-way ANOVA models

\begin{tabular}{|c|c|c|c|c|c|c|}
\hline \multicolumn{2}{|l|}{ Sources } & $\begin{array}{l}\text { Sum o } \\
\text { Squares }\end{array}$ & & $\begin{array}{l}\text { Mean } \\
\text { Square }\end{array}$ & & \\
\hline \multirow{3}{*}{$\begin{array}{l}\text { Auto- } \\
\text { nomous } \\
\text { learning }\end{array}$} & between groups & 1.502 & 2 & 0.751 & 3.824 & 0.026 \\
\hline & within groups & 17.485 & 89 & 0.196 & & \\
\hline & total & 18.987 & 91 & & & \\
\hline \multirow{3}{*}{$\begin{array}{l}\text { Interactive } \\
\text { learning }\end{array}$} & between groups & 2.407 & 2 & 1.204 & 4.693 & 0.012 \\
\hline & within groups & 22.824 & & 0.256 & & \\
\hline & total & 25.231 & 91 & & & \\
\hline
\end{tabular}

In the factor of autonomous learning, the $\mathrm{P}$ value between HLG and MLG is $0.225>0.05$ (Table 3), which indicates that there are no significant differences between HLG and MLG. The P value between HLG and LLG is $0.007<0.05$, which indicates that there are significant differences between HLG and LLG. The P value between MLG and LLG is $0.125>0.05$, which indicates that there are no significant differences between MLG and LLG.

Table 3. Multiple comparisons between groups ( $\mathrm{p}$ values)

\begin{tabular}{|c|c|c|c|c|c|}
\hline \multicolumn{3}{|c|}{ Autonomous learning } & \multicolumn{3}{|c|}{ Interactive learning } \\
\hline & $\mathrm{HLG}$ & MLG & & HLG & MLG \\
\hline MLG & 0.225 & & MLG & 0.022 & \\
\hline LLG & 0.007 & 0.125 & LLG & 0.005 & 0.571 \\
\hline
\end{tabular}

The plot of the mean of autonomous learning (Figure 1) vividly shows the differences among the groups. The distribution of the points of the three groups is almost in a steep straight line. MLG is located in the middle of the line, which explains no significant differences between HLG and MLG and between MLG and LLG, but significant differences between HLG and LLG.

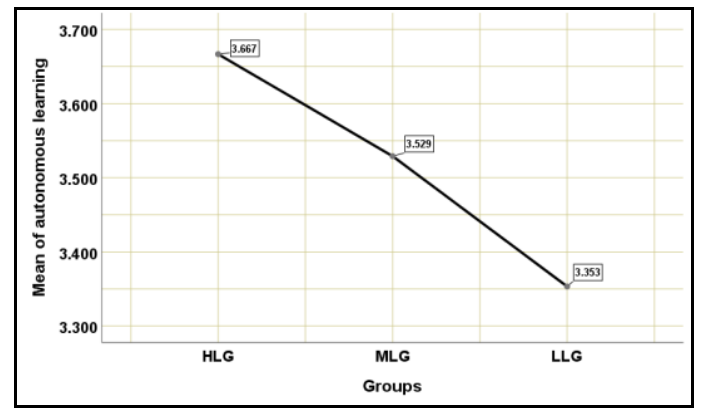

Figure 1 Mean of Autonomous learning

\subsubsection{Graduates’ English Interactive Learning}

In this part, a one-way ANOVA model is adopted once again. The factor in the model is graduates' English interactive learning. The total mean of interactive learning is 3.264 , with HLG the highest (3.518) and LLG the lowest (3.113) (Table 1).

The results of the one-way ANOVA model (Table 2) show that of the total variance of interactive learning (25.231), the source of between groups is 2.407 , and the source of within groups 22.824 . The $\mathrm{F}$ value of the model is 4.693 and the $\mathrm{P}$ value is $0.012<0.05$, which shows that this model is effective in the analysis of variance of the three groups.

In the factor of interactive learning, the $\mathrm{P}$ value between HLG and MLG is $0.022<0.05$ (Table 3), which indicates that there are significant differences between HLG and MLG. The P value between HLG and LLG is $0.005<0.05$, which indicates that there are also significant differences between HLG and LLG. The P value between MLG and LLG is $0.571>0.05$, which indicates that there are no significant differences between MLG and LLG.

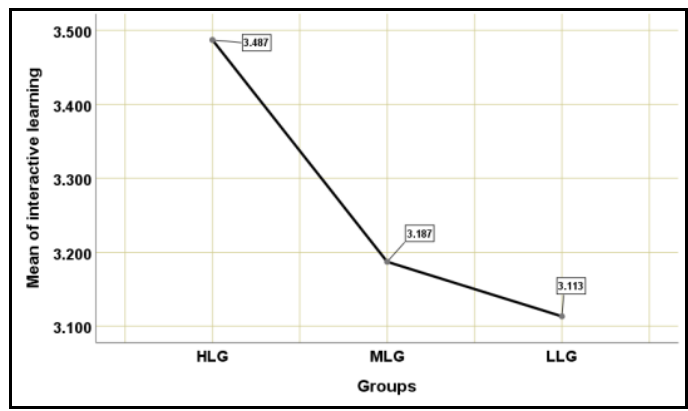

Figure 2 Mean of Interactive learning

The plot of the mean of interactive learning (Figure 2 ) vividly shows the differences among the three groups. While the trend from HLG to MLG is steep, the trend from MLG to LLG is gentle. The distribution of the points of the three groups explains significant differences between HLG and MLG and between HLG and LLG, but no significant differences between MLG and LLG.

\subsubsection{Graduates' Attitude to the Multimodal Teaching Mode Based on Rain Classroom}

The result of the questionnaire shows that the mean value of graduates' attitude to the multimodal teaching mode based on Rain Classroom is 4.122, which indicates that the graduates are very satisfied with the teaching mode. Most graduates think that the teaching mode has improved their interest in English learning, and also promoted their own autonomous learning ability. Most graduates think that the teaching mode makes them relaxed in the learning process. Most graduates believe that, compared with the traditional classroom, the Rain Classroom is more conducive to their academic ability. Therefore, most graduates adapt to the multimodal teaching mode based on Rain Classroom, and hope that the teacher continues to use the teaching mode. 


\subsubsection{Graduates' Views and Suggestions on the Multimodal Teaching Mode Based on Rain Classroom}

The final item of the questionnaire is an open-ended question, in which graduates are asked to share their views and suggestions on teachers' use of the multimodal teaching mode based on Rain Classroom. Most graduates say they are happy to be exposed to such an interesting teaching model and hope that teachers in other courses will also adopt the teaching model. Some graduates with poor self-control think that they cannot help but read the contents on the Internet or WeChat, and therefore interfere with their studies. Therefore, in the multimodal teaching mode based on Rain Classroom, teachers should strengthen the monitoring of students. Classroom activities should be well organized in order not to give students the opportunity to do other things.

\section{CONCLUSION}

This study finds that in the multimodal teaching mode based on Rain Classroom, graduates' completion of autonomous learning is relatively satisfactory. The vast majority of graduates are willing to learn autonomously before class and are confident of completing autonomous learning tasks on their own. Most graduates are satisfied with the effect of autonomous learning, can make and adjust the autonomous learning plan according to their own conditions, and can monitor and constantly optimize the autonomous learning process. Most graduates can solve their own problems or improve their weaknesses, and can take the initiative to collate and summarize knowledge and make reflection. Most graduates believe that the teaching materials and the teaching method are suitable for their own knowledge scope. Pre-class autonomous learning can help them to complete the self-study task.

Another finding of this study is that in the multimodal teaching mode based on Rain Classroom, the interactive learning of graduate students is also better than before. Most graduates interact with teachers and classmates on the Rain Classroom platform, and their classroom interaction with teachers and classmates is increased. Most of the graduates actively participate in group activities in the classroom, can confidently express their views, and carefully listen to other students. Through seminars, most graduates have a more comprehensive and in-depth grasp of what they have learned. It can be seen that most graduates are satisfied with the arrangement of interactive activities in class and after class.

\section{ACKNOWLEDGMENTS}

This work was financially supported by by Graduate Educational and Teaching Reform Project of Northwest Minzu University, Educational and Teaching Reform Project of Northwest Minzu University (Grant No. 2019XJJG-27), Talent Introduction Project of Northwest Minzu University (Grant No. xbmuyjrc2020005), Graduates' Research and Innovation Project (Grant No. Yxm2021052) and Innovation Team of Foreign Language Education Research (Grant No. 1110130137).

\section{REFERENCES}

[1] A. Bandura, Toward a psychology of human agency. Perspectives on Psychological Science, vol. 1(2), 2006, pp.164.

[2] J. Martin, Self-regulated learning, social cognitive theory, and agency, Educational psychologist, vol. 39(2), 2004, pp. 135-145.

[3] J. Reeve, C.M. Tseng, Agency as a fourth aspect of students' engagement during learning activities, Contemporary Educational Psychology, vol. 36(4), 2011, pp. 257-267.

[4] M. Taub, R. Sawyer, A. Smith, J. Rowe, R. Azevedo, J. Lester, The agency effect: The impact of student agency on learning, emotions, and problem-solving behaviours in a game-based learning environment, Computers \& Education, vol. 147, 2020, pp. 103781.

[5] H. Luo, T. Yang, J. Xue, M. Zuo, Impact of student agency on learning performance and learning experience in a flipped classroom, British Journal of Educational Technology, vol. 50(2), 2019, pp. 819-831.

[6] P. Wiliams, Student Agency for Powerful Learning, Knowledge Quest, vol. 45(4), 2017, pp. 8-15.

[7] P. Jääskelä, V. Heilala, T. Kärkkäinen, P. Häkkinen, Student agency analytics: learning analytics as a tool for analysing student agency in higher education, Behaviour \& Information Technology, 2020, pp. 1-19.

[8] M. Goller, S. Paloniemi, Agency at work, learning and professional development: An introduction, In Agency at Work. Springer, Cham, 2017, pp. 1-14.

[9] H. Zhang, Blended Teaching Mode Based on Rain Classroom in College English, Materials Science and Engineering, vol. 631, 2019, pp. 042024.

[10] H. Zhang, Application of Rain Classroom to College English Writing, Journal of Physics: Conference Series, vol. 1486, 2020, pp. 052020. 